\title{
PERBANDINGAN REFORMASI BIROKRASI PELAYANAN PUBLIK DI VIETNAM DAN INDONESIA (STUDI KASUS PROSEDUR DALAM MEMULAI BISNIS)
}

\author{
Irfan Winaldi \\ Magister Administrasi Publik Fakultas Ilmu Sosial dan Ilmu Politik, Universitas Padjadjaran \\ Bandung, Jawa Barat, Indonesia \\ winaldiirfan@gmail.com
}

\begin{abstract}
ABSTRAK
Penelitian ini mengenai perbandingan reformasi birokrasi pelayanan publik negara berkembang, yaitu Vietnam dan Indonesia. Penelitian ini mengambil data dari world bank dalam easy of doing business dengan mengukur salah aspek penilaian yaitu starting a business. Di dalam starting a business terdapat kategori dalam penilainnya, yaitu: jumlah prosedur yang dibutuhkan; berapa hari yang dibutuhkan; dan berapa biaya yang digunakan dalam memulai suatu bisnis. Dalam rangking yang dikeluarkan world bank di website Easy of Doing Business yang dihitung berdasarkan secara global Vietnam berada di rangking 70 sedangkan Indonesia sendiri berada di bawahnya yaitu rangking 73. Dari salah satu aspek easy of doing business yaitu starting a business. Peringkat Vietnam yang dihitung berdasarkan kawasan asia tenggara dan pasifik berada di atas Indonesia yaitu rangking 14 dari 25 negara, sedangkan Indonesia sendiri rangking 18 dari 25 negara. Penelitian menggunakan metode penelitian kualitatif dengan studi komparatif. Oleh karena itu penulis ingin melihat pebedaan antara Vietnam dan Indonesia dari segi reformasi birokrasi pelayanan public.
\end{abstract}

Kata Kunci: Reformasi Birokrasi, Pelayanan Publik, Bisnis.
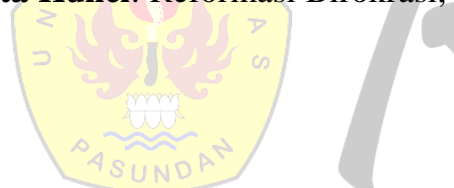

\section{ABSTRACT}

This research is about the comparison of the reform of the public service bureaucracy in developing countries, namely Vietnam and Indonesia. This study takes data from the world bank in easy of doing business by measuring one aspect of the assessment, namely starting a business. In starting a business, there are categories in its assessment, namely: the number of procedures required; how many days it will take; and how much it costs to start a business. In the ranking issued by the world bank on the Easy of Doing Business website, which is calculated based on the global ranking, Vietnam is ranked 70, while Indonesia itself is ranked 73. From one aspect of easy of doing business, namely starting a business. Vietnam's ranking, which is calculated based on the Southeast Asia and Pacific region, is above Indonesia, which is ranked 14th out of 25 countries, while Indonesia ranks 18th out of 25 countries. This research uses qualitative research methods with a comparative study. Therefore, the author wants to see the difference between Vietnam and Indonesia in terms of public service bureaucratic reform.

Keywords: Bureaucratic Reform, Public Service, Business.

\section{PENDAHULUAN}

Good Governance tumbuh menjadi paradigma baru yang diharapkan menjadi konsep yang mampu mengobati birokrasi yang saat ini dinilai sarat dengan korupsi, kolusi, dan nepotisme. (Ndue, 2005) menjelaskan dalam (Haning, 2018) bahwa dalam penyelenggaraan publik dibutuhkan sebuah birokrasi yang berkompeten untuk melaksanakan sebuah kebijakan, semua hal tersebut bermuara keapa konsep good governance. (Maryam, 2016) menjelaskan pelayanan publik merupakan roda penggerak utama dari good governance. Tolak ukur dari keberhasilan kinerja pemerintah melalui birokrasi salah satunya adalah melalui pelayanan publik. Kurniawan (2005:4) menjelaskan dalam 


\section{Kebijakan: Jurnal Ilmu Administrasi \\ Volume 11, Nomor 1, Januari 2020 \\ E-ISSN: 2656-2820 \\ P-ISSN 1829-5762}

(Cahyadi, 2016) pelayanan publik sendiri merupakan layanan yang diberikan untuk memenuhi keperluan kepentingan masyarakat yang disesuaikan dengan prosedur atau aturan yang telah ditetapkan Vietnam menjadi negara berkembang dengan ekonomi yang cukup besar dengan GDPnya sendiri didorong dari sektor investasi dan industri yang terus meningkat. PDB Vietnam tumbuh 6.7\% pada tahun 2019. Selain Vietnam, salah satu negara berkembang adalah Indonesia. Akan tetapi, PDB Indonesia pun diprediksi hanya akan tumbuh 5\% di 2019. Pertumbuhan ekonomi Indonesia tahun 2019 masih kalah dibanding Vietnam. Negara Vietnam sendiri tumbuh sekitar 6,7\%. Untuk mengembangkan ekonomi sebuah negara, salah satu yang perlu dilakukan adalah dengan melakukan reformasi birokrasi khususnya di pelayanan publik yang dilakukan di sektor ekonomi atau bisnis. Easy of doing business adalah suatu tolak ukur yang dibuat oleh world bank yang dapat digunakan oleh pemerintah untuk meninjau alur birokrasi kemudahan dalam berbisnis. World Bank (2018:12) menjelaskan ada beberapa kategori dalam penilaian easy doing of business, salah satunya kategori penilaiannya yaitu starting a business. World Bank mengatakan bahwa starting a business merupakan indeks untuk bagaimana negara melayani masyarakat dalam segi membuka perusahaan/bisnis.

Dalam rangking yang dikeluarkan world bank di website Easy of Doing Business yang dihitung berdasarkan secara global Vietnam berada di rangking 70 sedangkan Indonesia sendiri berada di bawahnya yaitu rangking 73. Dari salah satu aspek easy of doing business yaitu starting a business. Peringkat Vietnam yang dihitung berdasarkan kawasan asia tenggara dan pasifik berada di atas Indonesia yaitu rangking 14 dari 25 negara, sedangkan Indonesia sendiri rangking 18 dari 25 negara. Dari penjelasan di atas, penulis tertarik utnuk melihat perbandingan reformasi birokrasi yang dilakukan dalam pelayanan publik khususnya dalam aspek starting a business yang merupakan langkah awal masyarakat dalam memulai bisnis di negara Vietnam dengan membandingkannya dengan negara Indonesia.

\section{METODE}

Penulis menggunakan metode dalam artikel ini adalah dengan metode penelitian kualitatif dengan studi komparatif. Menurut Arikunto (2019) kualitatif merupakan metode bertujuan untuk mengumpulkan data maupun informasi mengenai status suatu fenomena yang ada. Metode kualitatif mampu mengungkap fenomena yang terjadi pada objek yang ingin diteliti. Adapun pendekatan studi komparatif. Menurut Sukmadinata (2012:79) studi perbandingan merupakan pendekatan yang dilakukan dengan membandingkan dua atau lebih kejadian, kondisi, program, data atau yang lainnya. Hudson (2007:3) menjelaskan bahwa studi komparatif dilakukan dengan cara membandingkan dua atau lebih data yang diteliti baik dengan membandingkan perbedaan maupun persamaan atas pemikiran tertentu. Dalam mengumpulkan data penulis menggunakan studi pustaka, yaitu dengan mencari data sekunder, dengan mempelajari berbagai literatur diantaranya buku artikel, maupun yang lainnya. Penggalian data dalam artikel ini sebagian besar melalui situs website milik world bank yaitu https://www.doingbusiness.org khususnya bagian negara vietnam dan negara indonesia, sedangkan sebagian yang dengan mempelajari buku dan jurnal terkait.

\section{PEMBAHASAN}

Easy of Doing Business (EODB) merupakan suatu rangking dari negara-negara yang dibuat oleh World Bank untuk mengukur indeks kemudahan dalam berbisnis. Semakin tinggi rangking ease of doing business suatu negara berarti pemerintahan negara tersebut semakin kondusif dalam menyelenggarakan bisnis. Ada 10 indikator yang World Bank gunakan untuk mengukur kemudahan berbisnis di sebuah negara: 
1. Starting a business

2. Dealing with construction permit

3. $\quad$ Getting electricity

4. $\quad$ Registering property

5. Getting credit

6. $\quad$ Protecting minority investors

7. Paying taxes

8. Trading across border

9. Enforcing contracts

10. Resolving insolvency

Dalam artikel ini penulis fokus pada salah satu aspek penilaian yaitu starting a business. Strating a business merupakan indikator yang mengukur bagaimana tahapan-tahapan dari warga negara untuk memulai sebuah bisnis. Starting a business mengukur dari segi tahapan-tahapn yang dilakukan, Waktu, biaya yang dibutuhkan untuk mendirikan Perseroan Terbatas. Starting a business diukur dari beberapa indikator tersendiri, yaitu:

1. Jumlah prosedur atau tahapan untu meresmikan sebuah perusahaan, dengan rincian yang dihitung dengan jumlah tahapanya. Adapun rinciannya sebagai berikut:

a. Pra-registrasi ( contoh: pendaftaran nama atau reservasi di notaris)

b. Melakukan registrasi di kota-kota yang mempunyai ekonomi bisnis yang besar

c. Post-registration ( contoh: pendaftaran jaiminan sosial)

d. Memperoleh persetujuan dari pasangan untuk memulai bisnis

e. Memperoleh dokumen resmi

2. Waktu yang dibutuhkan dalam menyelesaikan setiap prosedur dihitung berdasarkan jumlah hari yang diperlukan untuk menyelesaikan setiap prosedur tersebut

a. Setiap prosesdur harus mempunyai hari yang terpisah. Dua prosedur tidak bisa dimulai dihari yang sama

b. Prosedur online dicatat setengah hari

c. Prosedur dianggap selesai jika dokumen akhir yang dibuat dapat diterima

d. Tidak melakukan kontak dengan pejabat yang berwenang untuk mempercepat waktu prosedur

3. Biaya yang diperlukan untuk menyelesaikan prosedur

a. Dihitung dari biaya resmi, bukan dari biaya suap

b. Ada atau tidaknya biaya profesional kecuali biaya layanan yang diwajibkan oleh hukum

World bank menjelaskan dalam website Easy of Doing Business setiap negara mempunyai tahapan-tahapan dalam memulai sebuah bisnis dari membuat nama perusahaan sampai perusahaan tersebut menjadi resmi legal. Adapun Negara Vietnam mempunyai tahapan-tahapan untuk memulai bisnis atau mendirikan perusahan, yaitu: 
Tabel Prosedur memulai bisnis di Vietnam

\begin{tabular}{|c|c|c|c|}
\hline \multicolumn{2}{|c|}{ No. Tahapan } & Waktu & Biaya \\
\hline 1 & $\begin{array}{l}\text { Periksa nama perusahaan yang diusulkan, dapatkan } \\
\text { sertifikat bisnis dan pendaftaran pajak dan } \\
\text { mempublikasikan konten pendaftaran di National } \\
\text { Business Registration Portal (NBRP) } \\
\text { a. Untuk mendaftarkan perusahaan, pemohon harus } \\
\text { menyerahkan dokumen sesuai dengan yang ada di } \\
\text { peraturannya. } \\
\text { b. Setelah menerima dokumen tersebut, kantor } \\
\text { registrasi bisnis akan menginput kedalam sebuah } \\
\text { aplikasi pendaftaran bisnis nasional dan memeriksa } \\
\text { dokumen pendukung lainnya } \\
\text { c. Kantor Pendaftaran Bisnis akan mengeluarkan } \\
\text { sertifikat perusahaan selama } 3 \text { hari kerja jika dokumen- } \\
\text { dokumennya telah terpenuhi } \\
\text { d. Dalam } 5 \text { hari kerja setelah dikeluarkannya } \\
\text { sertifikat } \\
\text { Pendaftaran perusahaan regsitrasi bisnis harus } \\
\text { mengirimkan dokumen pendaftaran tersebut ke kantor } \\
\text { otoritas pajak, departemen statistik, departemen tenaga } \\
\text { kerja dan departemen asuransi sosial. Ull112l Illinl } \\
\text { f. Layanan online sebenarnya sudah tersedia, akan } \\
\text { tetapi dalam tindak lanjutnya memerlukan dokumen } \\
\text { dalam bentuk hardcopy dan justru memakan waktu lebih } \\
\text { lama. Sehingga orang-orang lebih mendaftarkannya } \\
\text { langsung melalui }\end{array}$ & 3 Hari & $\begin{array}{ll}\text { VND 100.000 (Jika } \\
\text { pendaftaran } & \text { online, } \\
\text { gratis); } & \text { VND } \\
300.000 & \text { untuk } \\
\text { publikasi } & \end{array}$ \\
\hline 2 & $\begin{array}{l}\text { Membuat segel resmi perusahaan perusahaan } \\
\text { Membuat stempel, cap, atau segel resmi perusahaan } \\
\text { bertujuan untuk membuka rekening di bank }\end{array}$ & 1 Hari & VND 450.000 \\
\hline 3 & $\begin{array}{l}\text { Mengirimkan pemberitahuan sampel segel resmi } \\
\text { perusahaan secara online Pengusaha harus } \\
\text { mengirimkan contoh sampel segel resmi perusahaan } \\
\text { secara online ke kantor registrasi bisnis }\end{array}$ & 1 Hari & Gratis \\
\hline 4 & Membuat rekening perusahaan di bank & 1 Hari & Gratis \\
\hline 5 & $\begin{array}{l}\text { Menyetujui bentuk faktur PPN sebelum dicetak } \\
\text { dengan Departemen Perpajakan } \\
\text { Perusahaan harus menggunakan faktur PPN yang } \\
\text { dicetak sendiri, dibeli atau juga bisa dilakukan secara } \\
\text { online Dibutuhkan sekitar } 10 \text { hari untuk mendapatkan } \\
\text { faktur PPN yang dicetak sendiri dan mendaftarkannya di } \\
\text { departemen perpajakan }\end{array}$ & 10 Hari & $\begin{array}{lll}\text { VND } & 200.000 & \text { per } \\
\text { buku } & & \end{array}$ \\
\hline 6 & $\begin{array}{l}\text { Membayar pajak lisensi bisnis Membayar pajak lisensi } \\
\text { bisnis harus dibayarkan di kantor otoritas pajak tempat } \\
\text { perusahaan mendaftarkan pajaknya. Pajak lisensi ini }\end{array}$ & $\begin{array}{l}\text { Kurang dari } \\
\text { sehari } \\
\text { (dilakukan } \\
\end{array}$ & $\begin{array}{lr}V N D & 2.000 .000 \\
\text { (pajak lisensi bisnis) }\end{array}$ \\
\hline
\end{tabular}


Kebijakan: Jurnal Ilmu Administrasi

Volume 11, Nomor 1, Januari 2020

E-ISSN: 2656-2820

P-ISSN 1829-5762

\begin{tabular}{|l|l|l|l|}
\hline No. & Tahapan & Waktu & Biaya \\
\hline & harus dibayarkan setiap tahun & $\begin{array}{l}\text { secara } \\
\text { online), } \\
\text { bersamaan } \\
\text { dengan } \\
\text { prosedur } \\
\text { sebelumnya }\end{array}$ & \\
\hline $\mathbf{7}$ & $\begin{array}{l}\text { Mendaftarkan karyawan perusahaan ke kantor } \\
\text { tenaga kerja } \\
\text { Dalam 30 hari sejak perusahaan beroperasi, pengusaha } \\
\text { harus mendaftarkan semua karyawan ke kantor tenaga } \\
\text { kerja }\end{array}$ & $\begin{array}{l}1 \\
\text { bersamaan } \\
\text { dengan } \\
\text { prosedur } \\
\text { sebelumnya }\end{array}$ \\
\hline $\mathbf{8}$ & $\begin{array}{l}\text { Mendaftarkan karyawan perusahaan ke dalam } \\
\text { asuransi sosial untuk asuransi keshetana dan sosial } \\
\text { karyawan perusahaan tersebut }\end{array}$ & $\begin{array}{l}\text { gratis } \\
\text { bersamaan } \\
\text { dengan } \\
\text { prosedur } \\
\text { sebelumnya }\end{array}$ & Gratis \\
\hline
\end{tabular}

Sumber: World Bank Doing Business, 2019

Dari tabel tersebut langkah-langkah dalam starting a business di negara Vietnam terdapat 8 prosedur agar perusahaan tersebut resmi atau legal. Waktu penyelesaian kesemua prosedur tersebut adalah 16 hari. Vietnam sendiri telah menyediakan layanan online untuk tahap awal layanan starting $a$ businessnya, akan tetapi karena hasil akhirnya harus mencetak dan menyerahkan dokumen langsung maka orang-orang lebih cendrung untuk datang ke kantornya langsung. World bank memberikan nilai Vietnam dari aspek starting a business adalah sebesar 85.1 (0-100). Untuk lebih jelasnya mengenai waktu yang dibutuhkan dan mekanisme starting a business negara Vietnam dijelaskan melalui gambar di bawah ini

Gambar Starting a Business di Vietnam

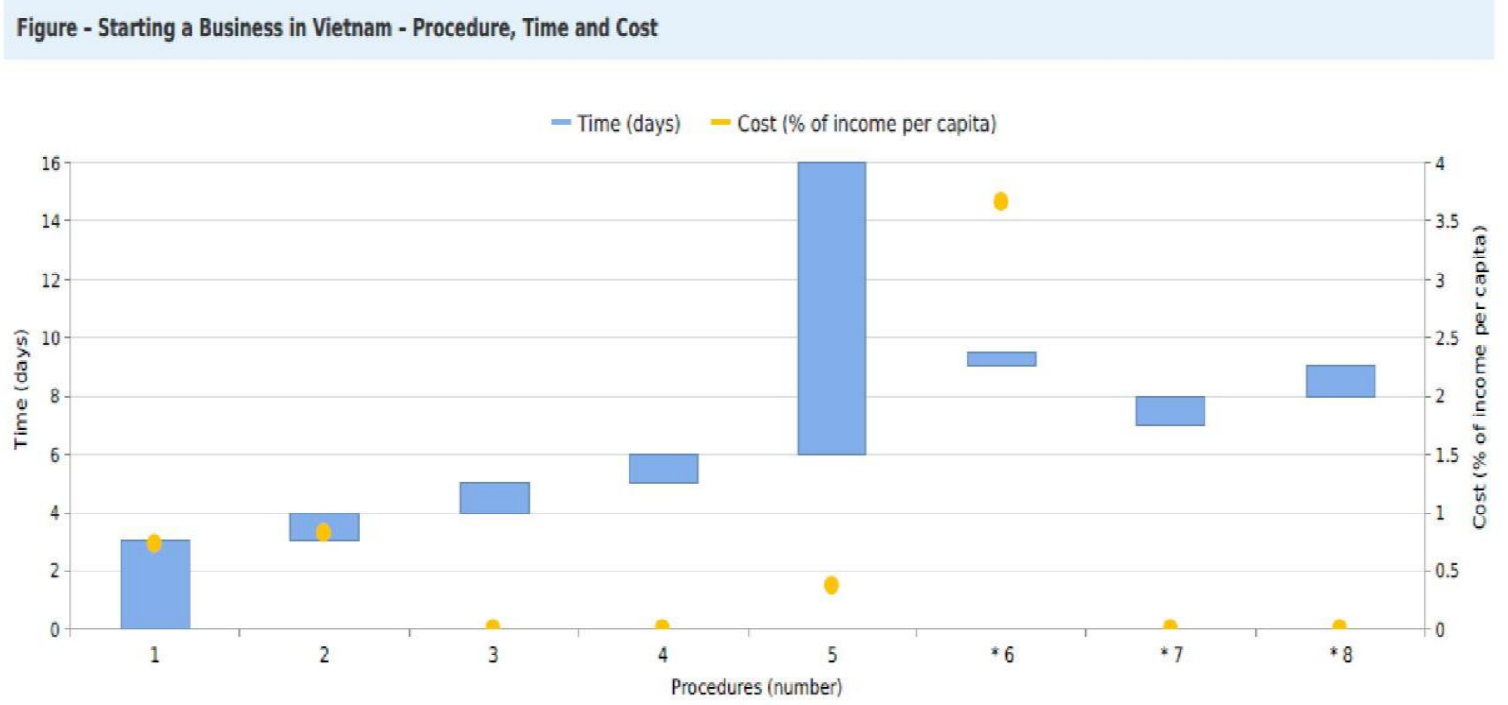

Sumber: World Bank Doing Business, 2019 
Kebijakan: Jurnal Ilmu Administrasi

Volume 11, Nomor 1, Januari 2020

E-ISSN: 2656-2820

P-ISSN 1829-5762

Sedangkan negara Indonesia, menurut World Bank tahapan-tahapan dalam memulai sebuah bisnis dari membuat nama perusahaan sampai perusahaan tersebut menjadi resmi adalah sebagai berikut :

\begin{tabular}{|c|c|c|c|}
\hline No. & Tahapan & Waktu & Biaya \\
\hline 1 & $\begin{array}{l}\text { Membayar biaya untuk mendapatkan izin } \\
\text { nama perusahaan Proses ini dilakukan secara } \\
\text { online melalui bantuan notaris untuk } \\
\text { mendapatkan nama resmi sebuah } \\
\text { perusahaan.Notaris harus membayar biaya Rp } \\
100.000 \text { untuk mendapatkan izin nama } \\
\text { perusahaan tersebut }\end{array}$ & $\begin{array}{l}\text { Kurang dari Satu hari } \\
\text { (Online) }\end{array}$ & Rp 100.000 \\
\hline 2 & $\begin{array}{l}\text { Mendapatkan izin nama perusahaan dari } \\
\text { Kementrian Hukum dan HAM Untuk } \\
\text { mendapatkan izin untuk nama perusahaan, } \\
\text { notaris memasukkan kode online saat } \\
\text { memesan nama perusahaan sebagai bukti } \\
\text { pembayaran, dengan mengikuti aturan-aturan } \\
\text { yang telah ditentukan }\end{array}$ & $\begin{array}{l}\text { Kurang dari Satu hari } \\
\text { (Online) }\end{array}$ & $\begin{array}{l}\text { Termasuk kedalar } \\
\text { prosedur ketiga }\end{array}$ \\
\hline 3 & $\begin{array}{l}\text { Membayar biaya penerimaan negara bukan } \\
\text { pajak (PNBP) sebagai biaya validasi dan } \\
\text { publikasi perusahaan }\end{array}$ & $\begin{array}{l}\text { Kurang dari Satu hari } \\
\text { (Online) }\end{array}$ & $\begin{array}{l}\text { Rp. } 500.000 \\
\text { (validasi } \\
\text { perusahaan sebaga } \\
\text { badan hukum) Rp } \\
430.000 \text { (publikasi) }\end{array}$ \\
\hline 4 & $\begin{array}{l}\text { Menyiapkan notaris untuk mebuatkan akta } \\
\text { perusahaan. Notaris harus mendapatkan } \\
\text { formulir standar untuk akta perusahaan, agar } \\
\text { pengusaha melengkapi dan meninjau sesuai } \\
\text { dengan ketentuan yang disepakati oleh } \\
\text { mereka. Notaris kemudian akan membuatkan } \\
\text { dokumen perusahaan (akta pendirian, akta } \\
\text { perusahaan). }\end{array}$ & 110 & $\begin{array}{l}\text { Tergantung modal } \\
\text { perusahaan }\end{array}$ \\
\hline 5 & Membuat cap perusahaan & 1 Hari & $\operatorname{Rp} 30.000$ \\
\hline 6 & $\begin{array}{l}\text { Mendisposisikan akta pendirian ke } \\
\text { Kementrian Hukum dan HAM Prosedur ini } \\
\text { dilakukan secara online dengan melampirkan } \\
\text { rekening bank perusahaan. Setelah melalui } \\
\text { beberapa tahapan, Kementrian Hukum dan } \\
\text { HAM akan mengeluarkan surat persetujuan } \\
\text { akta perusahaan secara online }\end{array}$ & $\begin{array}{l}\text { Kurang dari Satu hari } \\
\text { (Online) }\end{array}$ & $\begin{array}{l}\text { Termasuk kedalar } \\
\text { prosedur keenam }\end{array}$ \\
\hline 7 & $\begin{array}{l}\text { Mendaftar untuk mendapatkan surat } \\
\text { domisili perusahaan }\end{array}$ & 2 Hari & Gratis \\
\hline 8 & 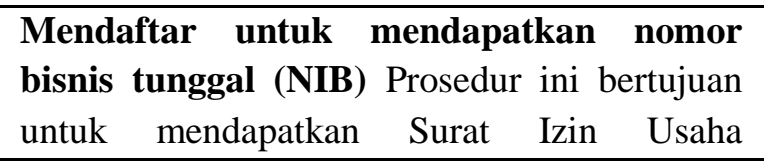 & 1 Hari & Gratis \\
\hline
\end{tabular}


Kebijakan: Jurnal Ilmu Administrasi

Volume 11, Nomor 1, Januari 2020

E-ISSN: 2656-2820

P-ISSN 1829-5762

\begin{tabular}{|c|c|c|c|}
\hline No. & Tahapan & Waktu & Biaya \\
\hline & $\begin{array}{l}\text { Perdagangan dan Tanda Daftar Perusahaan) } \\
\text { yang dilakukan online }\end{array}$ & & \\
\hline 9 & $\begin{array}{lccc}\text { Mendaftarkan } & \text { Tenaga } & \text { Kerja } & \text { ke } \\
\text { Kementerian Tenaga Kerja } & & \end{array}$ & 1 Hari & Gratis \\
\hline 10 & $\begin{array}{l}\text { Mendaftar untuk memperoleh } \\
\text { Ketenagakerjaan }\end{array}$ & 1 Hari & Gratis \\
\hline 11 & $\begin{array}{l}\text { Mendaftar ke Kantor Pajak untuk } \\
\text { memperoleh nomor pendaftaran wajib } \\
\text { pajak (NPWP) dan nomor pengumpul PPN }\end{array}$ & \begin{tabular}{|lr}
$\begin{array}{l}1 \\
\text { dengan }\end{array}$ & (bersamaan \\
sebelumnya)
\end{tabular} & Gratis \\
\hline
\end{tabular}

Sumber: World Bank Doing Business, 2019

Starting a business di Indoneisa mempunyai 11 prosedur agar perusahaan tersebut resmi atau legal. Penyelesaian waktu yang dibutuhkan agar kesemua prosedur tersebut adalah 13 hari. World bank memberikan nilai untuk Indonesia dari aspek starting a business adalah sebesar 81.2 (0-100). Untuk lebih jelasnya mengenai waktu yang dibutuhkan dan mekanisme starting a business negara Vietnam dijelaskan melalui gambar di bawah ini.

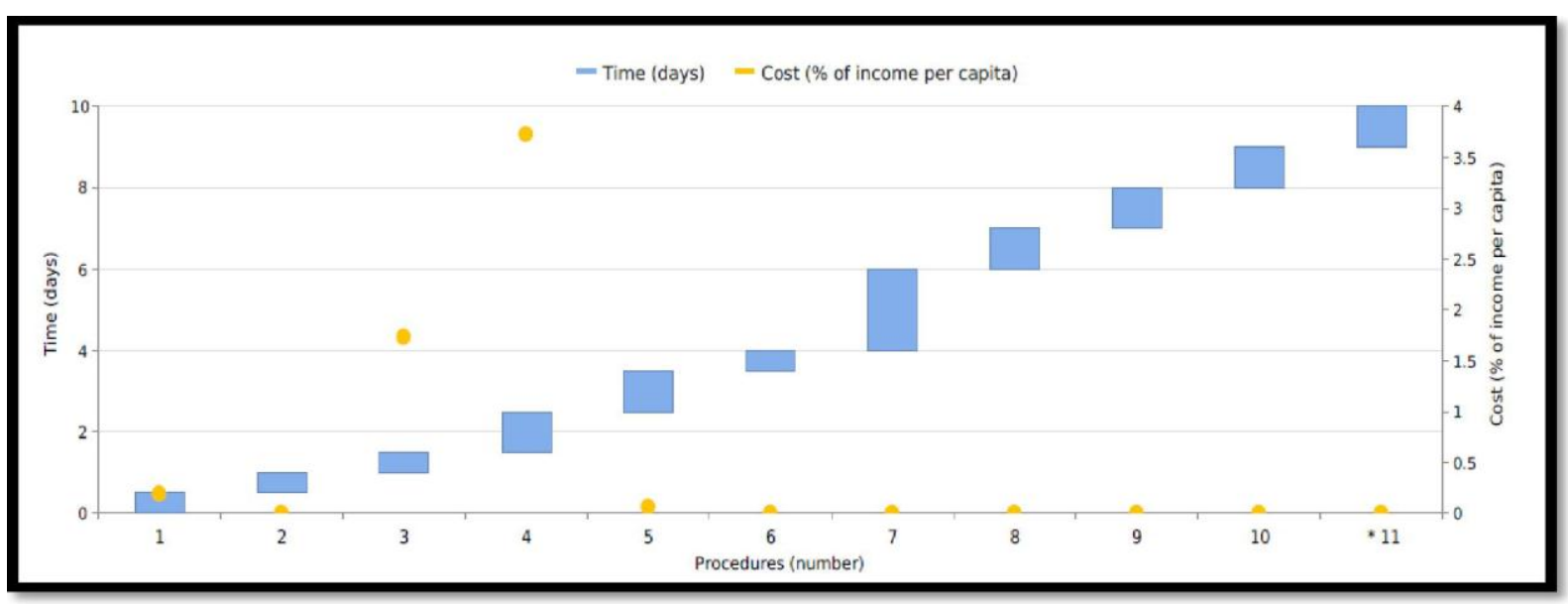

Sumber: World Bank Doing Business, 2019

Berikut adalah tabel perbandingan starting a business Vietnam dan Indonesia

\begin{tabular}{|l|l|l|}
\hline Indikator Starting a business & Vietnam & Indonesia \\
\hline Prosedur (Jumlah) & 8 & 11 \\
\hline Waktu (Hari) & 16 & 13 \\
\hline Biaya & 5.6 & 5.7 \\
\hline
\end{tabular}

Sumber: World Bank Doing Business, 2019

Dari segi prosedural Vietnam lebih sedikit dari Indonesia, Vietnam mempunyai 8 tahapan, sedangkan Indonesia mempunyai 11 langkah. Akan tetapi dari segi e-government Indonesia lebih banyak prosedur yang dilakukan melalui online daripada Vietnam. Waktu yang dibutuhkan Vietnam dalam starting a business aadalah sebesar 16 hari dan lebih banyak dibandingkan dengan Indonesia yang 13 hari. Sedangkan dari segi biaya yang dibutuhkan Indonesia lebih banyak daripada Vietnam. Dari sisi pelayanan publik, pengusaha atau masyarakat yang ingin mendaftarkan atau membuat 


\section{Kebijakan: Jurnal Ilmu Administrasi Volume 11, Nomor 1, Januari 2020 E-ISSN: 2656-2820 P-ISSN 1829-5762}

perusahaan bisnis sendiri langsung dibantu oleh Instansi pemerintah Vietnam yaitu kantor registrasi bisnis. Sedangkan di Indonesia harus melalui notaris terlebih dahulu. Dalam mengurus pendaftaran perusahaan bisnis Vietnam mempunyai lebih sedikit intanso yang dibutuhkan daripada di Indonesia. Vietnam hanya 3 yaitu : Dinas Pendaftaran Bisnis; Kantor Pajak; dan Dinas urusan tenaga kerja. Sedangkan Indonesia membutuhkan banyak intansi ada 5, yaitu : Notaris; Kementrian Hukum dan HAM; Kantor Pajak; Dinas Penanaman Modal Terpadu Satu Pintu; dan Dinas Tenaga Kerja

\section{KESIMPULAN}

Vietnam merupakan negara berkembang dengan ekonomi yang cukup besar dengan GDPnya sendiri didorong dari sektor investasi dan industri yang terus meningkat. Menurut World Bank di situs Easy of doing business. Vietnam merupakan negara yang cukup berkembang dalam melakukan reformasi birokrasi pelayanan khususnya pelayanan dalam hal membuka bisnis atau strating a business. Di bandingkan dengan negara asia tenggara lainnya seperti Indonesia Vietnam memiliki keunggulan tersendiri yaitu dari segi biaya dan prosedur. Walaupun sedikit melalui prosedur online, dibandingkan Indonesia Vietnam lebih unggul karena membutuhkan instansi yang lebih sedikit daripada Indonesia. Sehingga dari variabel diatas membuat negara Vietnam memiliki pertumbuhan PDB dan Rangking Easy of Doing Business yang lebih tinggi dibandingkan Indonesia.

\section{DAFTAR PUSTAKA}

Cahyadi, A. (2016). PENERAPAN GOOD GOVERNANCE DALAM PELAYANAN PUBLIK (Studi Tentang Kualitas Pelayanan Elektronik Kartu Tanda Penduduk Berbasis Good) Governance Di Kecamatan Sukolilo Surabaya). JPAP: Jurnal Penelitian Administrasi Publik, 2(02). https://doi.org/10.30996/jpap.v2i02.1004

Haning, M. T. (2018). Reformasi Birokrasi di Indonesia: Tinjauan Dari Perspektif Administrasi Publik. Analisis Kebijakan Dan Pelayanan Publik, 4(1), 25-37.

Maryam, N. S. (2016). Mewujudkan good governance melalui pelayanan publik. Jurnal Ilmu Politik Dan Komunikasi, VI(1), 1-18.

Pasolong, Harbani. 2007. Teori Administrasi Publik. Bandung: Alfabeta.

Satibi, Iwan. Manajemen Publik Dalam Perspektif Teoritik dan Empirik. 2012. Bandung: Unpas Press

Satibi, Iwan. Teknik Penulisan Skripsi, Tesis, dan Disertasi. Bandung: CEPLAS (Centre For Political and Local Autonomy Studies).

Siagian, Sondang P. Filsafat Administrasi. 2014. Jakarta : Bumi Aksara

Sugiyono. 2016. Metode Penelitian Kuantitatif, Kualitatif, dan R\&D. Bandung: Alfabeta.

Priansa, Donni Junni. 2018. Manajemen Organisasi Publik. Bandung: Pustaka Setia.

Website:

https://www.doingbusiness.org diakses pada tanggal 14 November 2019 pukul $19.30 \mathrm{WIB}$

http://eodb.ekon.go.id/ diakses pada tanggal 15 November 2019 pukul 20.30 WIB 